\title{
Producción de hidrógeno a partir de biogás mediante óxidos metálicos
}

\author{
J. Plou, C. Sanz, R. Campo, E. Segura, P. Durán, E. Romero, J. Herguido, J.Á. Peña \\ Catálisis, Separaciones Moleculares e Ingeniería del Reactor (CREG) \\ Instituto de Investigación en Ingeniería de Aragón (I3A)
}

Universidad Zaragoza, Mariano Esquillor s/n, 50018, Zaragoza, Spain. Tel.+34-876555487, e-mail: jplou@unizar.es

\begin{abstract}
La demanda energética actual se abastece principalmente mediante combustibles fósiles, pero las reservas mundiales están disminuyendo a gran velocidad y se estima que se agoten en las próximas décadas. A la inevitable escasez hay que añadir la contribución de estos combustibles al conocido como "efecto invernadero". La búsqueda de otras alternativas energéticas es por tanto urgente y perentoria, siendo el hidrógeno utilizado en pilas de combustible una de las referencias más eficientes, versátiles y prometedoras. El método de obtención de hidrógeno más ampliamente utilizado en la actualidad es el llamado reformado de metano con vapor de agua, que por el momento utiliza como materia prima combustibles fósiles como el gas natural. Dadas las actuales circunstancias, la investigación se está centrando en la utilización de biogás como fuente primaria para la obtención del hidrógeno. El biogás es el resultado de la digestión anaerobia de residuos orgánicos (urbanos, de ganado, de depuradora de aguas residuales,...), y tiene como componentes mayoritarios metano y dióxido de carbono. En el proceso conocido como "reformado seco", el metano reacciona catalíticamente con el propio dióxido de carbono contenido en el biogás. La mezcla resultante, que contiene una elevada proporción de hidrógeno, debe ser purificada previamente a su utilización. La propuesta del CREG consiste en utilizar óxidos de hierro con aditivos para llevar a cabo, tanto la producción como la purificación y de modo simultáneo en un mismo recipiente. Este proceso conocido como "steam-iron" consiste en dos etapas: de reducción del óxido mediante la corriente de gas, y de oxidación de hierro metálico mediante vapor de agua en el que se obtiene hidrógeno puro.
\end{abstract}

